\title{
The effect of exercising under particulate matter 2.5 conditions on forced vital capacity and blood lead levels
}

\author{
DOI: https://doi.org/10.5114/pq.2020.100288
}

\author{
Samsul Bahri', Dadan Resmana ${ }^{1}$, Haryo Satrio Tomo ${ }^{2}$, Tommy Apriantono ${ }^{1}$ \\ ${ }^{1}$ Department of Sport Science, Bandung Institute of Technology, Bandung, Indonesia \\ ${ }^{2}$ Faculty of Civil and Environmental Engineering, Bandung Institute of Technology, Bandung, Indonesia
}

\section{Abstract}

Introduction. The increase of air pollution in Indonesian big cities has resulted in serious health problems of their inhabitants Doing physical exercises in such conditions may affect health quality. This study aims to investigate the effects of physical exercises at public sports facilities exposed to particulate matter $2.5\left(\mathrm{PM}_{2.5}\right)$ on forced vital capacity (FVC) and blood lead levels among visitors of public sports centres in Bandung.

Methods. A pretest-posttest randomized-group design was applied. Overall, 30 people who visited public sports facilities were selected to participate on the basis of the inclusion criteria. The subjects were divided into 2 equal groups, the control and the experimental group. The experimental group performed physical exercises for an hour 3 times a week for 6 weeks under high $\mathrm{PM}_{2.5}$ conditions. Meanwhile, the control group did not perform any physical exercise. The participants underwent anthropometric measurements at baseline, as well as spirometry (FVC) and blood lead tests before and after the intervention. $\mathrm{PM}_{2.5}$ levels were also evaluated.

Results. There was a significant increase $(p<0.001)$ in FVC and blood lead levels in the experimental group after 6 weeks of exercising in the evening at public sports facilities which were highly exposed to $\mathrm{PM}_{2.5}$.

Conclusions. Six weeks of routine and regular physical exercises at public sports facilities highly exposed to $\mathrm{PM}_{2.5}$ increased blood lead levels, with no negative effect to body function in accordance with standard lead level values by the local health department.

Key words: physical exercises, air pollution, health, public sports facilities

\section{Introduction}

Air pollution has become a serious problem in all big cities around the world, including Bandung, the capital city of the West Java province in Indonesia [1]. The pollutants most commonly produced in air pollution cases are carbon dioxide, carbon monoxide, hydrocarbon, nitrogen oxide, and less than $10 \mu \mathrm{m}$ and $2.5 \mu \mathrm{m}$ particulates [2]. Less than $2.5 \mu \mathrm{m}$ particulates, commonly known as particulate matter $2.5\left(\mathrm{PM}_{2.5}\right)$, are the focus of this study because research on this particular pollutant has been very scarce [3]. Previous studies show that long-term exposure to $\mathrm{PM}_{2.5}$ causes a decrease in lung function [2] and that lead, one of the contents of $\mathrm{PM}_{2.5}$, affects human health [3].

The problem of air pollution may also influence all human activities, including physical exercise. Regular physical exercise has been proven not only to provide physiological benefits but also to improve health. Conversely, the lack of physical exercise will increase the risk of illness and the mortality rate. However, people living in urban areas are facing a threat when they want to do physical exercise. It is because they have to exercise in an environment with a high level of air pollution. Acute exposure to mixed exhaust during exercise can decrease lung and vascular function in healthy and asthmatic subjects [4]. Elevated PM levels have been observed at college athletic fields and elementary school playgrounds near high-traffic roads, and significant decreases in lung function have been reported among college soccer players whose practice fields are in close proximity to major highways [5].
Moreover, there are not many studies describing the effects of air pollution on people who exercise regularly in a long term. Some research has indicated that respiratory and other physical problems are affected by long-term exposure to air pollution [4, 5]. However, the long-term impact of air pollution, particularly the $\mathrm{PM}_{2.5}$ pollutant, on forced vital capacity (FVC) and blood lead levels have not been documented. Therefore, this study aims to explore the correlation between air pollution, especially the $\mathrm{PM}_{2.5}$ pollutant, and FVC and blood lead levels.

\section{Subjects and methods}

\section{Participants}

Overall, 30 visitors of a public sports facility volunteered to be subjects of this study. All participants were asked to fill in a health questionnaire, and it was found that they had no smoking history, cardiovascular diseases, or asthma. The exclusion criteria involved a cardiovascular or respiratory disease. The study was performed in the period of FebruaryMarch 2018.

\section{Study design}

The study used a parallel, 2-group, purposive sampling, pretest-posttest design to determine the effect of an independent variable on dependent variables. The independent variable was the high concentration of $\mathrm{PM}_{2.5}$, while the de-

Correspondence address: Dadan Resmana, Department of Sport Science, Bandung Institute of Technology, Ganesha Street 10, Bandung 40132, Indonesia, e-mail: resmanadadan@gmail.com 
pendent ones were FVC and blood lead levels. The participants were randomized by using a coin toss and divided into 2 groups: 15 were assigned to the experimental group, and the other 15 to the control group, who received no intervention.

\section{Protocol procedures}

Before commencing the exercise program, all of the subjects were tested to gather anthropometric, FVC, and blood sample data. The experimental group then underwent an intervention which involved physical exercise at a public sports facility in the evening under a condition of a high $\mathrm{PM}_{2.5}$ level. The exercise program was conducted regularly 3 times a week for 6 consecutive weeks. It consisted of 5 minutes of warming up, 50 minutes of sub-maximum physical exercises, and 5 minutes of cooling down. The members of the control group, on the other hand, performed their usual activities which did not involve physical exercise. Both groups were instructed not to change their diet and not to consume dangerous/illicit drugs during the course of the study. After 6 weeks, all of the subjects were tested again to obtain FVC and blood sample data.

\section{Measurements}

\section{$\mathrm{PM}_{2.5}$ concentration}

Weather stations and laser egg instruments were placed 10 meters above the ground. The sensors in those instruments recorded the data on temperature, humidity, and $\mathrm{PM}_{25}$ level in the air, which could be directly viewed through a 'breathing space' application on a smartphone.

\section{Forced vital capacity}

All of the subjects were asked to sit down and inhale as deeply as they could. Then, they were asked to exhale as much of the air (from their lungs) as they could into an SP10 spirometer, which recorded their FVC level.

\section{Blood lead level}

All participants were instructed to fast (not eating or drinking) and to avoid exerting activities in the evening prior to blood collection. Fifteen $\mathrm{cm}^{3}$ of blood was collected from their antecubital vena. The collected samples were kept in room temperature before being centrifuged, and the serum was then kept in a temperature of $-85^{\circ} \mathrm{C}$ (in a freezer) for analysis. The blood lead level was determined with atomic absorption spectrometry in Hiperkes Laboratory Bandung.

\section{Anthropometric data}

The subjects' weight $(\mathrm{kg})$, height $(\mathrm{cm})$, and body mass index $\left(\mathrm{kg} / \mathrm{m}^{2}\right)$ were measured by using an Omron Karada Scan HBF-375 device.

\section{Statistical analysis}

The values are presented as mean \pm standard deviation, and the repeated measure ANOVA was used to evaluate the pre-test and post-test FVC level. The independent $t$-test served to determine any differences of FVC and blood lead levels between the experimental and control groups. Statistical significance was accepted at the level of $p<0.05$, and the statistical analysis was performed with the use of the SPSS v. 21.0 software.

\section{Ethical approval}

The research related to human use has complied with all the relevant national regulations and institutional policies, has followed the tenets of the Declaration of Helsinki, and has been approved by the ethics committee of the University of Padjadjaran.

\section{Informed consent}

Informed consent has been obtained from all individuals included in this study.

\section{Results}

Table 1 shows the meteorological data for the Bandung Institute of Technology public sports facility at 19:00 during the period of February-March, when the members of the experimental group performed their physical exercises. The data resulted from real time measurements with a laser egg instrument installed besides the running tracks at the public sports facility.

The results of the laser egg measurements indicate that the average $\mathrm{PM}_{2.5}$ level during the period of the study, exactly at 19:00, when the subjects performed the physical exercises, was $73.94 \mu \mathrm{g} / \mathrm{m}^{3}$.

As reported in Table 2, the average age of the subjects indicates that they can be categorized as adolescents; their body mass index implies healthy (normal) weight on the ba-

Table 1. Characteristics of the study area

\begin{tabular}{|l|c|c|c|}
\hline Date & $\begin{array}{c}\mathrm{PM}_{2.5} \\
\left(\mu \mathrm{g} / \mathrm{m}^{3}\right)\end{array}$ & $\begin{array}{c}\text { Temperature } \\
\left({ }^{\circ} \mathrm{C}\right)\end{array}$ & $\begin{array}{c}\text { Humidity } \\
(\%)\end{array}$ \\
\hline $1 / 2 / 2018$ & 93 & 23 & 80 \\
\hline $4 / 2 / 2018$ & 89 & 24 & 88 \\
\hline $6 / 2 / 2018$ & 88 & 23 & 86 \\
\hline $9 / 2 / 2018$ & 86 & 22 & 78 \\
\hline $11 / 2 / 2018$ & 101 & 23 & 62 \\
\hline $13 / 2 / 2018$ & 90 & 24 & 75 \\
\hline $16 / 2 / 2018$ & 94 & 21 & 72 \\
\hline $18 / 2 / 2018$ & 93 & 23 & 74 \\
\hline $20 / 2 / 2018$ & 89 & 23 & 75 \\
\hline $23 / 2 / 2018$ & 97 & 22 & 73 \\
\hline $25 / 2 / 2018$ & 95 & 24 & 76 \\
\hline $27 / 2 / 2018$ & 108 & 23 & 72 \\
\hline $2 / 3 / 2018$ & 110 & 23 & 81 \\
\hline $4 / 3 / 2018$ & 102 & 24 & 80 \\
\hline $6 / 3 / 2018$ & 88 & 23 & 70 \\
\hline $9 / 3 / 2018$ & 90 & 22 & 78 \\
\hline $10 / 3 / 2018$ & 96 & 23 & 76 \\
\hline $12 / 3 / 2018$ & 98 & 22 & 79 \\
\hline $15 / 3 / 2018$ & 91 & 23 & 80 \\
\hline $\mathrm{PM}$ & $93-\mathrm{sati}$ & 23 & 23 \\
\hline
\end{tabular}

$\mathrm{PM}_{2.5}$ - particulate matter 2.5 (acceptable level: $66 \mu \mathrm{g} / \mathrm{m}^{3}$ ) 
Table 2. Anthropometric characteristics (mean $\pm S D$ ) of the study participants

\begin{tabular}{|l|c|c|}
\hline Parameter & $\begin{array}{c}\text { Experimental } \\
\text { group }\end{array}$ & $\begin{array}{c}\text { Control } \\
\text { group }\end{array}$ \\
\hline Age (years) & $18.50 \pm 0.50$ & $18.50 \pm 0.50$ \\
\hline Height $(\mathrm{cm})$ & $173.50 \pm 5.34$ & $171.28 \pm 5.06$ \\
\hline Weight $(\mathrm{kg})$ & $63.85 \pm 9.31$ & $59.07 \pm 6.81$ \\
\hline Body mass index $\left(\mathrm{kg} / \mathrm{m}^{2}\right)$ & $21.16 \pm 2.56$ & $20.16 \pm 2.36$ \\
\hline
\end{tabular}

Table 3. Comparison of the studied variables (mean $\pm S D$ ) before and after the intervention

\begin{tabular}{|l|l|c|c|c|}
\hline Variable & \multicolumn{1}{|c|}{ Group } & Pre-test & Post-test & $p$ \\
\hline \multirow{2}{*}{$\begin{array}{l}\text { Forced vital } \\
\text { capacity }(\mathrm{l})\end{array}$} & Experimental & $3.42 \pm 0.06$ & $3.78 \pm 0.06^{*}$ & 0.001 \\
\cline { 2 - 5 } & Control & $3.45 \pm 0.06$ & $3.46 \pm 0.06$ & 0.66 \\
\hline $\begin{array}{l}\text { Lead levels } \\
(\mu \mathrm{g} / \mathrm{dl})\end{array}$ & Experimental & $0.85 \pm 0.06$ & $1.01 \pm 0.09^{*}$ & 0.001 \\
\cline { 2 - 5 } & Control & $0.84 \pm 0.05$ & $0.87 \pm 0.08$ & 0.66 \\
\hline
\end{tabular}

* values significantly different $(p<0.005)$ between pre-test and post-test conditions (independent $t$-test)

sis of the nutritional status guidelines from the World Health Organization [6].

After 6 weeks of the intervention, in the experimental group, FVC and blood lead levels increased significantly $(p<$ 0.001 ) after performing the exercise program in the evening (Table 3).

\section{Discussion}

The results of the laser egg measurements indicate that the average $\mathrm{PM}_{25}$ level at the Bandung Institute of Technology public sports facility during the period of the study, exactly at 19:00, when the subjects performed the physical exercises, was $73.94 \mu \mathrm{g} / \mathrm{m}^{3}$. This value is rather high, but it does not exceed the ambient limit set by the government. The Decree of Minister of Environment and Forestry No. 12 of 2010 about the implementation of regional air pollution control stipulates that the daily (24-hour) ambient limit of air pollution is $66 \mu \mathrm{g} / \mathrm{m}^{3}$ and the yearly ambient limit is $15 \mu \mathrm{g} / \mathrm{m}^{3}$ [6]. The decree does not set the hourly ambient limit. Similarly, the regulation issued by the World Health Organization specifies that the daily (24-hour) ambient limit of $\mathrm{PM}_{2.5}$ in the air is $25 \mu \mathrm{g} / \mathrm{m}^{3}$ and the yearly limit is $10 \mu \mathrm{g} / \mathrm{m}^{3}[6,7]$. The regulation does not mention the hourly limit.

The high concentration of $\mathrm{PM}_{2.5}$ at 19:00, when the subjects performed their physical exercise, was due to an increase in traffic along Tamansari and Siliwangi Streets during the rush hour. Both streets surrounding the Bandung Institute of Technology public sports facility, where the study was conducted, were full of vehicles as people left their offices, schools, and universities at the time of the study. The data collected with the laser egg instrument installed at the public sports facility were similar to those reported in previous studies, which indicated that the $\mathrm{PM}_{2.5}$ concentration around Tamansari Street tended to increase during the rush hours in the evening and in the morning [2] and the highest $\mathrm{PM}_{25}$ exposure at the Bandung Institute of Technology public sports facility occurred in the evening. Other studies also mentioned that $\mathrm{PM}_{2.5}$ concentration was higher in the evening [8] and that in Bandung, it exceeded the standard limit of ambient air, reaching a relatively dangerous level at certain hours of the
The increase of FVC in the experimental group indicates that performing physical exercise in an environment with a high concentration of $\mathrm{PM}_{2.5}$ could increase FVC after 6 consecutive weeks of exercise performed 3 times a week. The findings of this study are different from those of previous research, which revealed that individuals exposed to $\mathrm{PM}_{2.5}$ for a certain period tended to exhibit a decrease in FVC. This difference might appear because the subjects of the previous studies only performed normal or daily activities in an environment with a high concentration of $\mathrm{PM}_{2.5}$ [9-11]. The present study shows that performing physical exercises at public sports facilities with high $\mathrm{PM}_{2.5}$ concentration increases rather than decreases the FVC level. Regularly implemented physical exercises could increase one's FVC by more than $10 \%$ [12]. Physical exercises could also improve endurance and the strength of respiratory muscles, which in turn would increase lung capacity [13, 14].

This study also implies that blood lead levels increased in both groups. However, the experimental group experienced a more significant increase $(p<0.05)$. This indicates that the chemical content in $\mathrm{PM}_{2.5}$ was lead, which originated from the vehicles passing along Tamansari and Siliwangi Streets, surrounding the public sports facility. Even though the experimental group experienced a significant increase in the blood lead level, it was still under the normal limit based on the Decree of Indonesian Ministry of Health No. 1406, 2002. The low level of blood lead in the experimental group was probably because the lead entering the body was secreted with urine and/or faeces [15].

\section{Limitations}

The limitation that needs to be acknowledged regarding the present study is the exercise intensity. Further research is recommended to determine if the intensity of exercise affects the investigated variables in susceptible populations.

\section{Conclusions}

This study revealed that the training group experienced a significant increase in FVC and blood lead levels after a training program applied as many as 3 times a week for 6 weeks in the evening under high $\mathrm{PM}_{2.5}$ conditions.

\section{Acknowledgements}

The authors express their gratitude to all individuals who volunteered to participate in this study.

\section{Disclosure statement}

No author has any financial interest or received any financial benefit from this research.

\section{Conflict of interest}

The authors state no conflict of interest.

\section{References}

1. Lestari P, Savitri. Atmospheric particulate concentration measured in an urban area Bandung. Pure Appl Geophys. 2003;160:107-116; doi: 10.1007/s00024-003-8768-5.

2. Qonitan FD, Lestari P, Tomo HS. Evaluation of continuous and filter-based methods for measuring $\mathrm{PM}_{25}$ mass concentration in Bandung urban area. In: The Third Joint Seminar of Japan and Indonesia Environmental Sustainability and Disaster Prevention. Jawa Barat: Institut Teknologi Bandung; 2015; 47-53.

3. Lestari P. Factors affecting blood lead level for school children in Bandung. J Purifikasi. 2007;7(2):1-6. 
4. Rundell KW. Effect of air pollution on athlete health and performance. Br J Sports Med. 2012;46(6):407-412; doi: 10.1136/bjsports-2011-090823.

5. Cutrufello PT, Smoliga JM, Rundell KW. Small things make a big difference: particulate matter and exercise. Sports Med. 2012;42(12):1041-1058; doi: 10.1007/ BF03262311.

6. World Health Organization, Regional Office for Europe. Health effects of particulate matter. Policy implications for countries in Eastern Europe, Caucasus and central Asia. Copenhagen: WHO; 2013. Available from: https:// www.euro.who.int/_data/assets/pdf_file/0006/189051/ Health-effects-of-particulate-matter-final-Eng.pdf.

7. World Health Organization. Global health risks. Mortality and burden of disease attributable to selected major risks. Geneva: WHO; 2009. Available from: https://www. who.int/healthinfo/global_burden_disease/GlobalHealthRisks_report_full.pdf [20.07.2019].

8. Vecchi R, Marcazzan G, Valli G. A study on nighttimedaytime PM10 concentration and elemental composition in relation to atmospheric dispersion in the urban area of Milan (Italy). Atmos Environ. 2007;41(10):21362144; doi: 10.1016/j.atmosenv.2006.10.069.

9. Fortoul TI, Rojas-Lemus M, Rodriguez-Lara V, CanoGutierrez G, Gonzalez-Villalva A, Ustarroz-Cano M, et al. Air pollution and its effects in the respiratory system. In: Khallaf M (ed.), The impact of air pollution on health, economy, environment and agricultural sources. Rijeka: InTech; 2011; 41-68.

10. Lagorio S, Forastiere F, Pistelli R, lavarone I, Michelozzi $P$, Fano V, et al. Air pollution and lung function among susceptible adult subjects: a panel study. Environ Health. 2006;5:11; doi: 10.1186/1476-069X-5-11.

11. Qian Z, Liao D, Lin H-M, Whitsel E, Rose K, Duan Y. Associations of long-term exposure to ambient particulates and ozone with lung function in American adults a population based study. Epidemiology. 2004;15(4):S46.

12. Wilmore JH, Costill DL, Kenney WL. Physiology of sport and exercise. Champaign: Human Kinetics; 2008.

13. Ganong WF. Review of medical physiology. New York: McGraw-Hill Medical; 2005.

14. Guyton AC, Hall JE. Textbook of medical physiology. Philadelphia: Elsevier Saunders; 2006.

15. Zhang R, Wilson VL, Hou A, Meng G. Source of lead pollution, its influence on public health and the countermeasures. Int J Health Animal Sci Food Safety. 2015;2(1): 18-31; doi: 10.13130/2283-3927/4785. 